\title{
A smoking cessation program as a resource for bladder cancer patients
}

\author{
Daniel Vilensky, MD; Nathan Lawrentschuk, MB BS, PhD, FRACS; Karen Hersey, RN; \\ Neil E. Fleshner, MD, FRCSC
}

Cite as: Can Urol Assoc J 2012; 6 (5):E167-E173. Epub May 1, 2011. http://dx.doi.org/10.5489/ cuaj. 10070

\section{Abstract}

Background: Continued tobacco use following a bladder cancer $(\mathrm{CaB})$ diagnosis puts patients at risk for other tobacco-associated diseases and has also been associated with heightened risks of treatment-related complications, tumour recurrence, morbidity and mortality. Our aim was to determine if patients with $\mathrm{CaB}$ who continue to smoke warrant a smoking cessation program as a resource for improving their prognosis and long-term health.

Methods: A cross-sectional quantitative questionnaire-based study was performed between January and April 2009. We surveyed patients with a pathologically confirmed diagnosis of $\mathrm{CaB}$ during their cystoscopy appointments at a single cancer centre.

Results: One hundred patients completed the survey with $72 \%$ of them admitting to smoking in their lifetime. A third of respondents smoked at the time of their diagnosis; $76 \%$ of patients who had been active smokers at the time of their diagnosis $(n=33)$ reported smoking at some point thereafter and 58\% continued to smoke. Among continued smokers, they were classified in the following categories: $26 \%$ were in "precontemplation," $5 \%$ in "contemplation," 16\% in "preparation," and 53\% in "action;" 37\% of patients who continued to smoke were interested in a hospital-based smoking cessation program. Overall, 70\% reported smoking as a risk factor for a poor $\mathrm{CaB}$ prognosis. The two most common barriers to quitting were "trouble managing stress and mood" and "fear of gaining weight."

Conclusion: Based on the data from our centre, patients with $\mathrm{CaB}$ who continue to smoke after their diagnosis warrant a smoking cessation program as a resource for improving prognosis and long-term health. Further research should focus on establishing an efficacious and cost-effective program that provides these patients with the resources they need to quit smoking.

\section{Résumé}

Contexte : L'usage continu du tabac après un diagnostic de cancer de la vessie fait courir aux patients un risque de contracter d'autres maladies associées à l'usage du tabac, et a aussi été associé à des risques accrus de complications liées au traitement, de récurrence de la tumeur, de morbidité et de mortalité. Notre but était de déterminer si les patients atteints de cancer de la vessie qui continuent de fumer ont besoin d'un programme d'abandon du tabac pour améliorer leur pronostic et leur santé à long terme.

Méthodologie : Une étude transversale quantitative par questionnaire a été réalisée entre janvier et avril 2009. Nous avons sondé des patients ayant reçu un diagnostic de cancer de la vessie confirmé par examens pathologiques pendant un rendez-vous pour cystoscopie dans un seul centre de traitement du cancer.

Résultats : Cent patients ont rempli le sondage, dont $72 \%$ qui ont avoué avoir fumé pendant une période de leur vie. Un tiers des répondants fumait au moment du diagnostic; $76 \%$ des patients qui étaient des fumeurs actifs au moment de leur diagnostic $(n=33)$ ont signalé avoir continué à fumer par après et $58 \%$ fumaient toujours. Ceux qui continuaient à fumer ont été répartis dans les catégories suivantes : $26 \%$ étaient en " précontemplation », $5 \%$ étaient en " contemplation », $16 \%$ en "préparation » et $53 \%$ en " action ». Trente-sept pour cent des patients qui continuaient de fumer souhaitaient participer à un programme d'abandon du tabac en milieu hospitalier. De façon globale, 70 \% ont signalé le tabagisme comme un facteur de risque de mauvais pronostic pour leur cancer de la vessie. Les deux principaux obstacles à l'abandon du tabac étaient la "difficulté à gérer le stress et l'humeur » et la " crainte de prendre du poids».

Conclusion : Selon les données provenant de notre centre, les patients atteints d'un cancer de la vessie qui continuent de fumer après leur diagnostic ont besoin d'un programme d'abandon du tabac pour améliorer leur pronostic et leur santé à long terme. D'autres études devraient porter sur l'établissement d'un programme efficace et rentable fournissant à ces patients les ressources nécessaires pour cesser de fumer.

\section{Introduction}

Bladder cancer $(\mathrm{CaB})$ remains a significant public health concern. In 2009, there were an estimated 6900 new cases of $\mathrm{CaB}$ in Canada, with more men affected than women. ${ }^{1}$ The incidence and burden on the health care system are increasing. ${ }^{2-6}$ It is well-established that tobacco use is the cause of bladder cancer in one-third to one-half of $\mathrm{CaB}$ cases, ${ }^{7-9}$ yet $\mathrm{CaB}$ related to tobacco use is still rising. ${ }^{9-11}$ Continued tobacco use following a $\mathrm{CaB}$ diagnosis has also been associated with worse disease-associated outcomes, such as tumour recurrence, progression to invasive disease and metastases, and the acquisition of secondary urinary 
tract carcinomas..$^{12-14}$ In addition, smoking is a well-known cause of chronic lung disease, heart disease, cerebrovascular disease and other malignancies..$^{15}$ It has recently been suggested, even by urologists, that patients with $\mathrm{CaB}$ should be targeted to undergo screening for lung cancer. ${ }^{16}$ In terms of cancer screening, smokers are also less likely to present to the doctor's office, thereby potentially worsening their long-term prognosis. ${ }^{17}$ Finally, patients with $\mathrm{CaB}$, particularly superficial stages of the disease, can often survive for many years after treatment and therefore should be advised on the importance of smoking cessation as a primary preventive measure for other tobacco-related illnesses. However, the degree to which urologists provide these smoking cessation services is unknown.

Helping patients diagnosed with $\mathrm{CaB}$ quit smoking has been considered a strategy to mitigate the extensive impact of this disease. There are many factors to consider when determining the need to initiate a smoking cessation program for this population. Firstly, the significant number of smokers with bladder cancer necessitates the initiation of a smoking cessation program. In a recent review, Strope and Montie concluded that current data on tobacco smoking prevalence among $\mathrm{CaB}$ patients are lacking. ${ }^{8}$ The data on the high prevalence of smokers and the willingness of $\mathrm{CaB}$ patients to quit smoking are over 12 years old and from a single centre. ${ }^{18}$ Secondly, the patient's understanding of smoking's impact on disease-related outcomes must be established; patients who perceive a higher risk of cancer recurrence with continued smoking are more likely to abstain. ${ }^{19}$ When patients at a urology clinic in the United States were surveyed about smoking as a risk factor for cancers, only $36 \%$ recognized bladder cancer as a risk of smoking, whereas $98 \%$ of patients recognized lung cancer as a risk. ${ }^{20}$ In the United Kingdom, one study demonstrated that only $13 \%$ of $\mathrm{CaB}$ patients with a history of smoking were aware that continued smoking could potentially worsen their prognosis, yet no similar studies have been done in North America. ${ }^{21}$ Lastly, it would be valuable to determine if there are common characteristics among smokers with $\mathrm{CaB}$ as well as commonly experienced barriers to quitting to elucidate how the needs of this subset of smokers differs from the average tobacco-user. The purpose of this study was to determine if patients with $\mathrm{CaB}$ who continue to smoke after their diagnosis warrant a smoking cessation program as a resource to improve their prognosis and long-term health.

To our knowledge, no study has empirically tested the effectiveness of smoking cessation interventions in this population. Nonetheless, this study demonstrates that tobacco addiction is a common comorbidity in $\mathrm{CaB}$ patients and these patients deserve a smoking cessation program. It must be accepted that such an addiction is a chronic, relapsing disease with many of the harmful secondary effects, such as $\mathrm{CaB}$, which take decades to manifest themselves. As such, programs for smoking cessation should encompass nicotine replacement products, pharmacotherapy and long-term behavioural support, which are all evidence-based treatments which have been extensively researched in the general population.

\section{Methods}

\section{Study design}

This is a single centre, cross-sectional study which used a quantitative questionnaire and retrospective chart review approved by the Research Ethics Board.

\section{Subjects}

Patients seen by urologic oncologists in the $\mathrm{CaB}$ clinic from January and June 2009 for follow-up cystoscopy of previously diagnosed or treated CaBs were screened consecutively for study eligibility. Requirements were pathologically confirmed $\mathrm{CaB}, \geq 18$ years age and written consent.

\section{Data collection}

Patients were approached, offered participation in the study and given the informed consent form to review and complete. Patients who completed the consent form were administered a validated questionnaire by a research team member. The questionnaire was a compilation of questions regarding risk perception, smoking and smoking cessation history and demographic data; the questionnaire was derived from 3 previously validated questionnaires used to investigate similar research questions. ${ }^{18,20,22}$ The compilation was adapted to meet the specific needs of this study. Stage and grade data for each patient was gathered using the University Health Network's CaB Informatics System (BLIS).

\section{Outcome measures}

For the purpose of this study, patients were classified as smokers (lifetime history of smoking $>100$ cigarettes) or non-smokers. Smokers were further classified as quitters or continued smokers. Quitters were even further classified as having quit prior to their $\mathrm{CaB}$ diagnosis, immediately after (within 1 week) $\mathrm{CaB}$ diagnosis, or sometime after ( $>1$ week after) $\mathrm{CaB}$ diagnosis.

All patients were asked whether or not they perceived smoking and other factors to affect the course of their $\mathrm{CaB}$ and other malignancies. This study reports the percentage of $\mathrm{CaB}$ patients who are aware that continued smoking leads to a poorer prognosis of their $\mathrm{CaB}$. 
Smoking cessation program for bladder cancer patients

\begin{tabular}{|c|c|c|c|c|c|}
\hline Overall & $\begin{array}{l}\text { No. patients who } \\
\text { have never smoked }\end{array}$ & $\begin{array}{l}\text { No. patients who } \\
\text { have quit smoking }\end{array}$ & $\begin{array}{l}\text { No. continued } \\
\text { smokers }\end{array}$ & $\begin{array}{l}\text { Total no. } \\
\text { patients }\end{array}$ & $p$ value $^{b}$ \\
\hline Sex & (28) & (53) & (19) & $(100)$ & \\
\hline $\mathrm{M}$ & 20 & 41 & 9 & 70 & \multirow{2}{*}{$p<0.05$} \\
\hline $\mathrm{F}$ & 8 & 12 & 10 & 30 & \\
\hline \multicolumn{6}{|l|}{ Age } \\
\hline $19-39$ & 0 & 3 & 1 & 4 & $p<0.75$ \\
\hline $40-49$ & 1 & 0 & 2 & 3 & \\
\hline $50-59$ & 7 & 13 & 5 & 25 & \\
\hline $60-69$ & 7 & 13 & 4 & 24 & \\
\hline $70-79$ & 6 & 13 & 4 & 23 & \\
\hline $80-89$ & 7 & 11 & 3 & 21 & \\
\hline \multicolumn{6}{|l|}{ Race/ethnicitya } \\
\hline Caucasian & 23 & 47 & 18 & 88 & \\
\hline Black & 0 & 3 & 0 & 3 & \\
\hline Asian & 5 & 1 & 0 & 6 & $p<0.10$ \\
\hline Middle Eastern & 0 & 1 & 1 & 2 & \\
\hline Interracial & 0 & 1 & 0 & 1 & \\
\hline \multicolumn{6}{|l|}{ Education } \\
\hline High school or less & 7 & 18 & 13 & 38 & \\
\hline Some college/vocational training & 10 & 27 & 4 & 41 & $p<0.005$ \\
\hline Graduate/doctoral degree & 11 & 8 & 2 & 21 & \\
\hline \multicolumn{6}{|l|}{ Family income } \\
\hline Less than $\$ 49,999$ & 7 & 11 & 6 & 24 & \\
\hline$\$ 50,000$ to 99,999 & 10 & 15 & 2 & 27 & \\
\hline$\$ 100,000$ or more & 5 & 14 & 6 & 25 & $p<0.50$ \\
\hline Prefer not to answer & 5 & 9 & 3 & 17 & \\
\hline Doesn't know & 1 & 4 & 2 & 7 & \\
\hline \multicolumn{6}{|l|}{ Marital status } \\
\hline Never married & 6 & 2 & 0 & 8 & \\
\hline Married/marriage-like relationship & 16 & 42 & 16 & 74 & $p<0.05$ \\
\hline Divorsed/separated/widowed & 6 & 9 & 3 & 18 & \\
\hline Second primary cancer diagnosis & 8 & 16 & 6 & 30 & $p<0.97$ \\
\hline
\end{tabular}

$a=$ race/ethnicity statistics were determ demographic variables.
differences in smoking status between de

Patients who continued to smoke at the time of assessment were categorized according to Prochaska's Model of Change. ${ }^{23}$ Patients were classified as being in "precontemplation" (not currently thinking about quitting), "contemplation" (thinking about quitting in the next 6 months), "preparation" (planning on quitting within 1 month) or "action" (currently taking action to quit).

In addition, this study examined common characteristics among smokers with $\mathrm{CaB}$. For each patient, the following data were documented: first language, age, gender, barriers to quitting, ethnicity, education, family income, interest in a hospital-based smoking cessation program and experiences with attempts at quitting. Chi-squared analysis was used to test for associations between quitting and patient demographics (Microsoft Excel, Microsoft Corporation and GraphPad Prism 4.0, GraphPad Software Inc., San Diego, CA).

\section{Results}

The study samples' demographic data are summarized (Table 1). Of the 100 eligible study participants, 70\% were male, $88 \%$ were Caucasian and $74 \%$ were married or in a marriage-like relationship. At the time of data collection, the median time since diagnosis was 3 years; $30 \%$ of patients had a second primary cancer diagnosis in their lifetime, 55\% had carcinoma in situ or $\geq \mathrm{T} 1$ disease, with $67 \%$ of these patients with high-grade disease.

Smoking status and intention to quit data are summarized (Table 2). Of all the participants, $72 \%$ admitted to smoking in their lifetime and 33\% smoked at time of diagnosis. At the time of data collection, $19 \%$ of patients continued to smoke. Moreover, $76 \%$ of patients who had been active smokers at the time of diagnosis $(n=33)$ reported smoking at some point after the diagnosis and 58\% continued to smoke at 
Vilensky et al.

\begin{tabular}{lcccc}
\hline Table 2. Smoking status and intention to quit data & & & \\
\hline Overall & $\begin{array}{c}\text { No. patients } \\
\text { (N) }\end{array}$ & $\begin{array}{c}\text { Patients who continue } \\
\text { to smoke (\%) }\end{array}$ & $\begin{array}{c}\text { Patients with history } \\
\text { of smoking (\%) }\end{array}$ & $\begin{array}{c}\text { Total patients } \\
\text { (\%) }\end{array}$ \\
\hline History of smoking (>100 cigarettes) & $(100)$ & & & 72.0 \\
Yes & 72 & 100 & - & 28.0 \\
No & 28 & - & 45.8 & 33.0 \\
Smoked at time of diagnosis & 33 & 100 & 73.6 & 53.0 \\
Quitters & 53 & - & 54.1 & 39.0 \\
Quit before diagnosis & 39 & - & 11.1 & 8.0 \\
Quit immediately after diagnosis & 8 & - & 8.3 & 6.0 \\
Quit sometime after diagnosis & 6 & - & 26.4 & 19.0 \\
Continue to smoke everyday & 19 & 100 & 6.9 & 5.0 \\
Precontemplation & 5 & 26.3 & 1.4 & 1.0 \\
Contemplation & 1 & 5.3 & 4.2 & 3.0 \\
Preparation & 3 & 15.8 & 13.9 & 10.0 \\
Action & 10 & 52.6 & - & - \\
Interest in a hospital-based & 7 & 36.8 & & \\
smoking cessation program & & & & \\
\hline a = Only asked to continued smokers. Of the 7 patients who were interested in a hospital-based smoking cessation program, 6 were in action and 1 was in \\
preparation.
\end{tabular}

the time of assessment. Twenty-four percent of patients who smoked at diagnosis $(n=33)$ quit immediately after. Those who admitted to smoking in their lifetime averaged 31 pack/ years and patients who continued to smoke at the time of their assessment averaged 37 pack/years; this difference, however, was not significant $(p<0.25)$

Among patients who continued to smoke daily at the time of study $(\mathrm{n}=19), 26 \%$ were in "precontemplation," $5 \%$ were in "contemplation," $15.8 \%$ were in "preparation," and $53 \%$ were in "action," In addition, 7 (37\%) patients who continued to smoke at the time of study expressed an interest in a hospital-based smoking cessation program.

With regard to the perception of smoking as a risk factor for a poor cancer prognosis, $70 \%$ of respondents knew that smoking is a risk factor for a poor $\mathrm{CaB}$ prognosis compared to $93 \%$ for poor lung cancer prognosis, $51 \%$ for colon cancer prognosis, $50 \%$ for prostate cancer prognosis and $45 \%$

\begin{tabular}{lc}
\hline $\begin{array}{l}\text { Table 3. Barriers to quitting tobacco use reported by bladder cancer patients who } \\
\text { continue to smoke }\end{array}$ & Patients who continue to smoke, N (\%) \\
\hline & 19 \\
\hline & $1(5.3)$ \\
Lack of social support & $1(5.3)$ \\
Lack of access to resources & $0(0.0)$ \\
Language barriers & $1(5.3)$ \\
Not interested in quitting & $4(21.1)$ \\
Trouble managing stress and mood & $2(10.5)$ \\
Trouble affording cessation aids or medications & $4(21.1)$ \\
Afraid of gaining weight & $5(26.3)$ \\
Other &
\end{tabular}

$\mathrm{a}=$ Other answers given included: "started smoking at a funeral as a cigarette was being passed around - a reflex action to an old habit;" "habit;" "addiction was too strong;" "wanted to start again;" "helping mother after accident, mother smokes." for renal cancer prognosis (data not shown). Among patients who continued to smoke at the time of assessment $(n=19)$, the risk perception of smoking was similar to the overall group (68\%) for a poor CaB prognosis (data not shown). Patients without post-secondary education were less likely to perceive smoking as a risk factor for a poor $\mathrm{CaB}$ prognosis; the difference, however, was not significant (odds ratio $[O R]=0.89 ; p<0.8)$. Similarly, patients with a family income $<\$ 100000$ were less likely to perceive smoking as a risk factor for poor $\mathrm{CaB}$ prognosis; again, the difference was not significant $(\mathrm{OR}=0.53 ; 0.2<p<0.3$ ) (data not shown).

We documented the common barriers to quitting smoking for continued smokers with $\mathrm{CaB}$ (Table 3). The 2 most common barriers identified by patients were "trouble managing stress and mood" (21\%) and "afraid of gaining weight" $(21 \%)$. "Trouble affording cessation aids or medications" was also expressed $(11 \%)$. Patients without post-secondary educations were significantly more likely to continue smoking than those with post-secondary education at the point of assessment $(\mathrm{OR}=4.21$; $0.001<p<0.01)$. Conversely, having a family income $<\$ 100,000$ was not significantly associated with continuing to smoke at assessment $(\mathrm{OR}=0.79 ; 0.50<p<0.70)$.

We also outlined the common smoking cessation methods used by quitters and continued smokers (Table 4). Overall, 72 respondents tried 98 smoking cessation methods. Quitting "cold turkey," without the 
Smoking cessation program for bladder cancer patients

\begin{tabular}{|c|c|c|c|c|c|c|c|c|c|}
\hline & $\begin{array}{l}\text { Number of } \\
\text { smokers }\end{array}$ & $\begin{array}{l}\text { Cold } \\
\text { turkey }\end{array}$ & $\begin{array}{l}\text { Self-help } \\
\text { material }\end{array}$ & $\begin{array}{l}\text { Formal } \\
\text { cessation } \\
\text { program }\end{array}$ & $\begin{array}{l}\text { Consult } \\
\text { with } \\
\text { doctor }\end{array}$ & $\begin{array}{c}\text { Nicotine } \\
\text { replacement } \\
\text { therapy }\end{array}$ & $\begin{array}{c}\text { Medication: } \\
\text { bupriorion } \\
\text { hydrochloride }\end{array}$ & $\begin{array}{l}\text { Medication: } \\
\text { varenicline }\end{array}$ & Other \\
\hline Total & (72) & 59 & 6 & 1 & 3 & 12 & 7 & 4 & 6 \\
\hline Quitters & 53 & 46 & 3 & 0 & 1 & 5 & 3 & 1 & 5 \\
\hline Quit before diagnosis & 39 & 33 & 2 & 0 & 1 & 4 & 2 & 0 & 5 \\
\hline $\begin{array}{l}\text { Quit immediately after } \\
\text { diagnosis }\end{array}$ & 8 & 8 & 0 & 0 & 0 & 0 & 0 & 0 & $\mathbf{0}$ \\
\hline $\begin{array}{l}\text { Quit sometime after } \\
\text { diagnosis }\end{array}$ & 6 & 5 & 1 & 0 & 0 & 1 & 1 & 1 & $\mathbf{0}$ \\
\hline
\end{tabular}

use of any aids or support, was by far the most commonly tried method.

\section{Discussion}

The benefits of smoking cessation are substantial. ${ }^{15,24}$ Today, patients diagnosed with $\mathrm{CaB}$, especially non muscle-invasive disease, can live longer lives, yet are at risk of other tobacco-associated diseases. In addition, continued tobacco use in $\mathrm{CaB}$ patients has been associated with heightened risks of tumour recurrence, progression and secondary urinary tract carcinomas. ${ }^{12}$ Further, preoperative smoking has been shown to increase surgical mortality risk intraoperatively, as well as postoperative complications. ${ }^{25}$ While there is evidence that smoking cessation likely benefits individuals in this population, a recent review concluded that current population-based data on the prevalence of tobacco smoking among $\mathrm{CaB}$ patients is needed to fully assess the potential of smoking cessation as a health improvement strategy in this population. ${ }^{8}$ The goal of this present study was to determine if patients with $\mathrm{CaB}$ who continue to smoke after diagnosis warrant a smoking cessation program by establishing the prevalence of smoking among $\mathrm{CaB}$ patients and documenting their intention to quit, their perception of the risk of smoking on $\mathrm{CaB}$ outcomes and common characteristics among smokers with bladder cancer.

The prevalence of a positive smoking history ( $>100$ cigarettes per lifetime) within our population was $72 \%$ and the prevalence of smoking at the time of diagnosis was 33\%. These results are relatively consistent with past studies and imply that there are many newly diagnosed patients who continue to smoke. ${ }^{18}$ Furthermore, these rates are higher than in the general population in Canada, in which the prevalence of tobacco users is about $17 \%{ }^{30}$ However, smoking rates among $\mathrm{CaB}$ patients are representative of rates of patients with other malignancies. ${ }^{26,27}$ While giving a cancer diagnosis is considered by many to be a "teachable moment" to counsel smoking cessation strategies, unfortunately $76 \%$ of patients who had been active smokers at the time of diagnosis $(n=33)$ reported smoking at some point after their diagnosis and 58\% continued to smoke at the time of assessment. Ostroff and colleagues investigated a population 12 years ago using a similar inclusion criteria and published somewhat more optimistic results; their patients, however, were assessed slightly longer after their diagnosis on average and therefore had more opportunity to quit. ${ }^{18}$ Nonetheless, nicotine addiction is a common comorbid condition among $\mathrm{CaB}$ patients and therefore warrants the provision of evidence-based treatments like any other disease entity.

Understanding a smoker's willingness to quit is helpful in recommending the appropriate cessation interventions and ensuring retention and compliance. ${ }^{13}$ This study used Prochaska's Model of Change to categorize continued smokers with $\mathrm{CaB} .{ }^{23}$ About a quarter of continued smokers expressed no interest in quitting within 6 months ("precontemplation"). Traditionally, these patients do not adhere to most interventions, but efforts can be focused on increasing motivation and education. The Canadian Cancer Society offers "One Step at a Time," a program which provides patients in the "precontemplation" and "contemplation" stages with educational material to help them quit. ${ }^{28} \mathrm{~A}$ similar approach may benefit "precontemplative" smokers with $\mathrm{CaB}$. This highlights one of the weaknesses of Prochaska's Model of Change in that patients currently not actively seeking to quit (i.e., in the "precontemplative" stage) have the potential to be ignored, even unintentionally, in favour of those expressing a desire to quit. In reality, such patients can be considered more worthy of smoking cessation resources. For example, the Canadian Cancer Society also offers the "Smoker's Helpline Quit Connection," a referral program which is accessible to physicians to connect their patients with smoking cessation counselling in their communities. ${ }^{31}$ Moreover, $16 \%$ and $53 \%$ of continued smokers with $\mathrm{CaB}$ are in "preparation" and "action" stages, respectively. These patients are more likely to adhere to conventional and betterstudied approaches to cessation (e.g., nicotine replacement therapy, pharmacotherapy and behavioural support) and represent most continued smokers. ${ }^{29}$ 
Vilensky et al.

It has been well-established that there is poor public perception that smoking is a risk factor for developing $\mathrm{CaB}$, but this is only the second study to investigate $\mathrm{CaB}$ patients' perception of the risk of smoking on the prognosis of their disease..$^{20,21}$ On our cross-sectional analysis, $70 \%$ of all patients with $\mathrm{CaB}$ and $68 \%$ of continued smokers with $\mathrm{CaB}$ were aware that smoking was a risk factor for poorer $\mathrm{CaB}$ diagnosis. These groups were much more likely to be aware of smoking as a risk factor for a negative lung cancer prognosis, suggesting that the status quo approach to counseling patients with $\mathrm{CaB}$ on the risks of continued smoking at our cancer centre is insufficient. Patients who perceive a higher risk of cancer recurrence with continued smoking are more likely to abstain from smoking. ${ }^{19}$ Better education for patients at the time of a diagnosis of $\mathrm{CaB}$ may encourage smoking cessation. A second indicator of insufficient patient education is that most patients who attempt to quit do so "cold turkey," despite evidence that this approach is less effective than nicotine replacement, pharmacotherapy or behavioural support. ${ }^{30}$ Particular attention should be paid to patients with less formal education, as they were more likely to continue to smoke. It must also be recognized that smoking cessation, as part of disease management, cannot be considered an isolated event (e.g., a hospital treatment program), but must be provided in a longitudinal fashion that includes counselling to increase readiness and prevent relapse. In summary, quitting smoking is not a one-time event; the treatment goal should be sustained abstinence. Finally, expecting $\mathrm{CaB}$ patients to quit smoking altogether because of their frightening diagnosis or expecting a pamphlet to be an effective intervention are not realistic and may actually further marginalize this vulnerable population.

Currently, our cancer centre does not have a formal policy on managing smoking cessation in patients with CaB. The support offered by urologists in our centre varies, but typically includes brief advice and seldom involves referral to specific community-based resources beyond their family physician. Despite current efforts, this study has shown that many patients with $\mathrm{CaB}$ continue to smoke and few patients who have attempted to quit are successful. A more intensive approach is an in-hospital smoking cessation program, which may be beneficial in larger cancer centres, such as ours. In this study, $37 \%$ of patients who continued to smoke at the time of assessment expressed an interest in such a program. While this percentage in not convincingly high, all of the interested patients were either in the "preparation" or "action" stages and represented a clear majority of patients in these two stages. In Ontario, the most notable hospitalbased program was developed by the University of Ottawa Heart Institute. ${ }^{31}$ Its protocol assesses the smoking status of every patient admitted regardless of their disease; patients are visited by a nurse visit during the hospital stay who offers them assistance, including cessation medications with patient follow-up and educational resources post-discharge. Remarkably, the success rate with this model is about $50 \%$, resulting in its expansion across Canada.

Our study has several limitations. Data were obtained from patients with $\mathrm{CaB}$ presenting to the cystoscopy clinic at a single centre. Participants were not randomly selected, therefore the generalizability of our findings to other samples may be questioned. In addition, we did not record who was offered the survey, but did not complete it and thus, we could not calculate the response or participation rate. Our questionnaire was only offered in English and no translator was available; as such, we may have introduced a selection bias. Some patients who were not fluent in English used a family member as a translator which may have skewed their answers.

\section{Conclusions}

In the cancer centre, in which this study was performed, patients with $\mathrm{CaB}$ who continue to smoke after diagnosis warrant a smoking cessation program as a resource for improving prognosis and long-term health. Among patients with $\mathrm{CaB}$ who were seen for cystoscopy, there was a high prevalence of continued smoking, a moderate perception of risk of continued smoking and a high willingness to quit. Moreover, difficulty with managing stress and mood and fear of gaining weight were the most commonly identified barriers to quitting in this population. Further research should focus on establishing an efficacious and cost-effective program that provides patients with $\mathrm{CaB}$ the resources they need to quit.

Department of Urology and Surgical Oncology, University Health Network, Princess Margaret Hospital and Toronto General Hospital, Toronto, University of Toronto, ON

Acknowledgements: We would like to acknowledge the assistance of Meerna Khatcherian from the Department of Urology at Princess Margaret Hospital in assisting with administration of surveys.

Competing interests: None declared.

This paper has been peer-reviewed.

\section{References}

1. Canadian Cancer Society's Steering Committee: Canadian Cancer Statistics 2009, Toronto. Canadian Cancer Society, 2009. www.cancer.ca/statistics. Accessed April 11, 2011.

2. Cagiannos I, Morash C. Surveillance strategies after definitive therapy of invasive bladder cancer. Can Urol Assoc J 2009;3:S237-42.

3. Ehdaie B, Smith SC, Theodorescu D. Personalized medicine in advanced urothelial cancer: when to treat, how to treat and who to treat. Can Urol Assoc J 2009;3:S232-6. 
Smoking cessation program for bladder cancer patients

4. Fradet Y. Screening for bladder cancer: the best opportunity to reduce mortality. Can Urol Assoc J 2009;3:S180-3.

5. Nepple KG, $0^{\prime}$ Donnell MA. The optimal management of TI high-grade bladder cancer. Can Urol Assoc J 2009;3:S188-92.

6. Yafi FA, Kassouf W. Radical cystectomy is the treatment of choice for invasive bladder cancer. Can Urol Assoc J 2009;3:409-12.

7. Cohen SM, Johansson SL. Epidemiology and etiology of bladder cancer. Urol Clin North Am 1992;19:4218.

8. Strope SA, Montie JE. The causal role of cigarette smoking in bladder cancer initiation and progression, and the role of urologists in smoking cessation. J Urol 2008;180:31-7; discussion 37.

9. Colin P, Koenig P, Ouzzane A, et al. Environmental factors involved in carcinogenesis of urothelial cell carcinomas of the upper urinary tract. BJU Int 2009;104:1436-40.

10. Baris D, Karagas MR, Verill C, et al. A case-control study of smoking and bladder cancer risk: emergent patterns over time. J Natl Cancer Inst 2009:101:1553-61.

11. Nieder AM, Mackinnon JA, Fleming LE, et al. Bladder cancer clusters in Florida: identifying populations at risk. J Urol 2009; 182:46-50; discussion 51.

12. Fleshner N, Garland J, Moadel A, et al. Influence of smoking status on the disease-related outcomes of patients with tobacco-associated superficial transitional cell carcinoma of the bladder. Cancer 1999;86:2337-45.

13. Kamat AM, Lotan YR. Perioperative Intravesical Therapy after transurethral resection for bladder cancer. J Urol 2010;183:19-20.

14. Lund L, Jacobsen J, Clark P, et al. Impact of comorbidity on survival of invasive bladder cancer patients, 1996-2007: A Danish population-based cohort study. Urology 2010 75:393-8. Epub 2009 Nov 14.

15. Dresler CM, Leon ME, Straif K, et al. Reversal of risk upon quitting smoking. Lancet 2006;368:348-9.

16. Del Rey J, Placer J, Vallmanya F, et al. Are patients with non-muscle-invasive bladder cancer a suitable population for a lung cancer screening trial? BJU Int 2010;106:49-52. Epub 2009 Nov 17.

17. Byrne MM, Davila EP, Zhoo W, et al. Cancer screening behaviors among smokers and non-smokers. Cancer Epidemiol 2010;34:611-7. Epub $2010 \mathrm{Jul} 23$.

18. Ostroff J, Garland J, Moadel A, et al. Cigarette smoking patterns in patients after treatment of bladder cancer. J Cancer Educ 2000;15:86-90.

19. Hay JL, Ostroff J, Burkhalter J, et al. Changes in cancer-related risk perception and smoking across time in newly-diagnosed cancer patients. J Behav Med 2007;30:131-42.
20. Nieder AM, John S, Messina CR, et al. Are patients aware of the association between smoking and bladder cancer? J Urol 2006;176:2405-8; discussion 2408.

21. Dearing J. Disease-centred advice for patients with superficial transitional cell carcinoma of the bladder. Ann R Coll Surg Engl 2005;87:85-7.

22. Centers for Disease Control and Prevention (USA). Behavioral Risk Factor Surveillance System Questionnaire; December 31, 2007.

23. Prochaska J0, Velicer WF. The transtheoretical model of health behavior change. Am J Health Promot 1997:12:38-48.

24. Lotan Y, Elias K, Svatek RS, et al. Bladder cancer screening in a high risk asymptomatic population using a point of care urine based protein tumor marker. J Urol 2009; 182:52-7; discussion 58.

25. Theadom A, Cropley $M$. Effects of preoperative smoking cessation on the incidence and risk of intraoperative and postoperative complications in adult smokers: a systematic review. Tob Control 2006;15:352-8.

26. Logan HL, Fillingim RB, Bartoshuk LM, et al. Smoking status and pain level among head and neck cancer patients. J Pain 2010:11:528-34.

27. Cowling DW, Yang J. Smoking-attributable cancer mortality in California, 1979-2005. Tob Control 2010;19 (Suppl 1):i62-7.

28. Canadian Cancer Society. One Step at a Time. hittp://www.cancer.ca/Ontario/Publications.aspx?sc_ lang=en. Accessed April 11, 2011.

29. Velicer W, Prochaska J, Fava J, et al. Smoking cessation and stress management: applications of the transtheoretical model of behavior change. Homeostasis 1998;38.

30. Coleman T. ABC of smoking cessation. Use of simple advice and behavioural support. BMJ 2004;328:3979.

31. Ministry of Health and Long Term Care (Ontario-Canada). The Ottawa Model for Smoking Cessation, a network's success: simply smoke free. http://www.health.gov.on.ca/english/providers/program/ cdpm/pdf/ottawa.pdf . Accessed April 11, 2011.

32. Ministry of Health Promotion. (Ontario-Canada). News Release: McGuinty Government Supports Innovative Smoking Cessation Program. http://www.mhp.gov.on.ca/en/news/2005/110905.asp. Accessed April $11,2011$.

Correspondence: Dr. Neil Fleshner, Division of Urology, Department of Surgical Oncology, Princess Margaret Hospital, 610 University Ave 3-130, Toronto, ON M5G 2M9; fax: 416-598-9997; neil.fleshner@uhn.on.ca 